\title{
Influence of Sample Pretreatment on the Analysis of High Contents of Rare-Earth and High Field Strength Elements in Geological Samples by ICP-AES and ICP-MS
} (Case Study of the Tomtor Deposit)

\author{
Bagai-ool Yu. Saryg-ool*a Lidiya N. Bukreeva ${ }^{a}$, \\ Irina N. Myagkaya ${ }^{a}$, Aleksandr V. Tolstov ${ }^{b}$, \\ Elena V. Lazareva ${ }^{a}$ and Sergey M. Zhmodik ${ }^{a}$ \\ ${ }^{a}$ Sobolev Institute of Geology and Mineralogy SB RAS \\ Novosibirsk, Russian Federation \\ ${ }^{b} P J S C$ «ALROSA»
}

Mirny, Republic of Sakha (Yakutia), Russian Federation

Received 22.10.2020, received in revised form 14.11.2020, accepted 05.12.2020

\begin{abstract}
Influence of sample pretreatment on the analysis of the high contents of rare earth (REE) and high field strength (HFSE) elements in geological samples by inductively coupled plasma atomic emission spectrometry (ICP-AES) and inductively coupled plasma mass spectrometry (ICP-MS) was studied. The rocks and rich ores of the Tomtor Nb-REE deposit were explored. Complete dissolution of the geological samples with a high content of "refractory" minerals has been achieved using fusion with a sodium peroxide. The results obtained by ICP-AES and ICP-MS after chemical dissolution are comparable with the results obtained by the XRF-SR without chemical pretreatment.
\end{abstract}

Keywords: Tomtor, rare earth elements, high field strength elements, sample preparation, fusion, acid digestion.

Citation: Saryg-ool B.Yu., Bukreeva L.N., Myagkaya I.N., Tolstov A.V., Lazareva E.V., Zhmodik S.M. Influence of sample pretreatment on the analysis of high contents of rare-earth and high field strength elements in geological samples by ICP-AES and ICP-MS (case study of the Tomtor deposit), J. Sib. Fed. Univ. Chem., 2020, 13(4), 593-605. DOI: 10.17516/1998-2836-0208

(C) Siberian Federal University. All rights reserved

This work is licensed under a Creative Commons Attribution-NonCommercial 4.0 International License (CC BY-NC 4.0).

* Corresponding author E-mail address: sarygool@igm.nsc.ru 


\title{
Влияние химической пробоподготовки
}

на определение высоких содержаний редкоземельных

и высокозарядных элементов

в геологических образцах методами ИСП-АЭС и ИСП-МС (на примере пород и руд месторождения «Томтор»)

\author{
Багай-оол Ю. Сарыг-оола ${ }^{\mathrm{a}}$, Л.Н. Букреева ${ }^{\mathrm{a}}$, И.Н. Мягкая \\ А.В. Толстов ${ }^{\tilde{\sigma}}$ Е.В. Лазарева ${ }^{\mathbf{a}}$, С.М. Жмодик ${ }^{\mathrm{a}}$ \\ ${ }^{a}$ Институт геологии и минералогии им. В.С. Соболева СО РАН \\ Российская Федерация, Новосибирск \\ ${ }^{\sigma} A K « A Л P O C A »(П А O)$ \\ Российская Федерачия, Республика Саха (Якутия), Мирньй
}

Аннотащия. В работе изучено влияние химической пробоподготовки на определение высоких содержаний редкоземельных (РЗЭ) и высокозарядных (ВЗЭ) элементов в геологических образцах методами атомно-эмиссионной спектрометрии с индуктивно-связанной плазмой (ИСП-АЭС) и масс-спектрометрии с индуктивно-связанной плазмой (ИСП-МС). Изучались породы и богатые руды Томторского ниобий-редкоземельного месторождения. Предложена методика сплавления с пероксидом натрия геологических образцов с высоким содержанием «упорных» минералов, при котором достигается полное вскрытие пробы. Результаты анализа методами ИСП-АЭС и ИСП-МС с химической пробоподготовкой сопоставлены с результатами, полученными методом РФА-СИ без химической пробоподготовки.

Ключевые слова: Томтор, редкоземельные элементы, высокозарядные элементы, химическая пробоподготовка, сплавление, кислотное разложение.

Цитирование: Сарыг-оол, Багай-оол Ю. Влияние химической пробоподготовки на определение высоких содержаний редкоземельных и высокозарядных элементов в геологических образцах методами ИСП-АЭС и ИСП-МС (на примере пород и руд месторождения «Томтор») / Багай-оол Ю. Сарыг-оол, Л.Н. Букреева, И.Н. Мягкая, А.В. Толстов, Е.В. Лазарева, С.М. Жмодик // Журн. Сиб. федер. ун-та. Химия, 2020. 13(4). С. 593-605. DOI: 10.17516/1998-2836-0208

\section{Введение}

Редкоземельные элементы (РЗЭ) согласно номенклатуре ИЮПАК включают элементы ряда лантаноидов ( $\mathrm{La}, \mathrm{Ce}, \mathrm{Pr}, \mathrm{Nd}, \mathrm{Pm}, \mathrm{Sm}, \mathrm{Eu}, \mathrm{Gd}, \mathrm{Tb}, \mathrm{Dy}, \mathrm{Ho}, \mathrm{Er}, \mathrm{Tm}, \mathrm{Yb}$ и Lu), а также Sc и Y. На сегодняшний день эти металлы относятся к критически важным для ряда современных технологий [1], поэтому исследования, посвященные определению содержаний РЗЭ в различных объектах $[2,3]$, весьма актуальны. Возрастание потребления РЗЭ приводит к необходимости разведки и включения в разработку новых месторождений $[4,5]$, поисков альтернативных/нетрадиционных источников этих элементов [6], а также изучения их негативного влияния на окружающую среду и живые организмы [7, 8]. Содержание и особенности распределения вы- 
сокозарядных элементов (В3Э: Ti, Zr, Nb, Hf, Ta, Th, U, зачастую к ним причисляют также РЗЭ) в горных породах используют в различных геолого-геохимических исследованиях [9].

При определении РЗЭ и ВЗЭ в геологических объектах применяется широкий спектр современных аналитических методов [2]. Однако ключевую роль в получении точных и достоверных данных играет именно правильно подобранная методика химической пробоподготовки. Высокие содержания РЗЭ и ВЗЭ, например, в рудах определяют напрямую после разложения минеральными кислотами или сплавлением, без дополнительных манипуляций [10-12]. В большинстве случаев для анализа требуется предварительное концентрирование из-за их низких содержаний или отделение от матричных элементов для устранения помех при анализе $[1,3]$. Особое внимание необходимо уделять полному разложению образца: известно, что некоторые минералы-носители РЗЭ и ВЗЭ (оксиды ВЗЭ, циркон, ксенотим и т.д.) являются «упорными» и поэтому требуют более жестких условий разложения [11, 13, 14]. В ИГМ СО РАН разработана и успешно применяется методика разложения образцов сплавлением с метаборатом лития $\mathrm{LiBO}_{2}$ в платиновых тиглях и последующим анализом методом масс-спектрометрии с индуктивно-связанной плазмой (ИСП-МС) [18], но присутствие сульфидов в веществе служит для данной методики мешающим фактором.

В данном исследовании было проведено сравнение методов химической пробоподготовки геологических образцов (сплавление с пероксидом натрия $\mathrm{Na}_{2} \mathrm{O}_{2}$, разложение смесью минеральных кислот $\mathrm{HF}-\mathrm{HClO}_{4}-\mathrm{HNO}_{3}-\mathrm{HCl}$ ), применяемых при определении Р3Э и В3Э методами массспектрометрии с индуктивно-связанной плазмой (ИСП-МС) и атомно-эмиссионной спектрометрии с индуктивно-связанной плазмой (ИСП-АЭС). Результаты ИСП-АЭС- и ИСП-МС-анализа были сопоставлены с результатами, полученными методом рентгенофлуоресцентного анализа на синхротронном излучении (РФА-СИ), не требующем химической пробоподготовки.

Для экспериментов были выбраны образцы руд и пород, вскрытых скважиной № 6151 (глубиной 500 м) на Томторском ниобий-редкоземельном месторождении, расположенном на севеpe Республики Саха (Якутия). Скважина № 6151 пробурена в пределах участка Буранный [15] и вскрывает наиболее полный разрез Томторского месторождения: юрские морские отложения, пермские континентальные угленосные отложения, богатые ниобий-редкоземельные руды, породы коры выветривания и кальцитовые карбонатиты.

\section{Методы исследования}

\section{Образиы руд и пород}

Для экспериментов были выбраны три образца из скважины № 6151 с разным химическим составом: ТР-37 (глубина 62.6-64.1 м); ТР-48 (глубина 77.3-77.8 м); ТР-215 (глубина 491-505 м). Образцы представляют собой среднее по указанным интервалам, пробы были истерты и хорошо гомогенизированы при разведке месторождения. Авторы в 2013 г. вывезли пробы с керносклада в пос. Амакинский.

Химическая пробоподготовка сплавлением с $\mathrm{Na}_{2} \mathrm{O}_{2}$ и определение РЗЭ и ВЗЭ методами ИСП-АЭС и ИСП-МС

Навеску образца массой 100 мг помещали в корундовый стаканчик, добавляли 1 г пероксида натрия (гранулированный для анализа, >95%, фирма Merck kGaA, Франция), смесь тщательно 
перемешивали. Корундовый стаканчик ставили в фарфоровый тигель во избежание загрязнения от стенок муфельной печи. Смесь предварительно сушили в муфельной печи в течение 40 мин при температуре $200{ }^{\circ} \mathrm{C}$, затем сплавляли при температуре $760{ }^{\circ} \mathrm{C}$ в течение 15 мин. После охлаждения корундовые стаканчики помещали в стеклянные стаканы на 50 мл, в стакан добавляли 30 мл $6 \mathrm{M} \mathrm{HCl}$ (ос.ч.) и нагревали на плите в течение 20 мин. Охлажденный раствор количественно переносили $1 \mathrm{M}$ раствором $\mathrm{HCl}$ в полипропиленовую пробирку на 50 мл, где предварительно было добавлено 0.5 мл 5\%-го раствора НF (ос.ч.), необходимого для стабилизации в растворе ВЗЭ. Объем раствора в пробирке доводили до 50 мл $1 \mathrm{M}$ раствором $\mathrm{HCl}$ и перемешивали.

Измерения проводили на атомно-эмиссионном спектрометре с индуктивно-связанной плазмой IRIS Advantage (Thermo Jarrell Ash, США) в ЦКП Многоэлементных и изотопных исследований СО РАН (аналитик С.Ф. Нечепуренко). Калибровку осуществляли с применением водных растворов элементов с аттестованными содержаниями. Относительная погрешность анализа не превышает 15 \%. Контроль точности определения РЗЭ методом ИСП-АЭС проводили с использованием отраслевых стандартных образцов ОСО 250-91 (НФС-23, руда редкоземельная, ВИМС, Россия), ОСО 755-16 (VIMS039RzO, руда ниобий-редкоземельная, ВИМС, Россия), ОСО 758-16 (VIMS042RzO, руда ниобий-редкоземельная, ВИМС, Россия).

Параллельно измерения проводили на масс-спектрометре с индуктивно-связанной плазмой высокого разрешения ELEMENT (Finnigan Mat, Германия) в ЦКП Многоэлементных и изотопных исследованиях СО РАН (аналитик И.В. Николаева). Методика и ее метрологические характеристики описаны в работе [18].

\section{Химическая пробоподготовка разложением}

смесью минеральных кислот и определение РЗЭ и ВЗЭ методом ИСП-МС

Разложение образцов проводили согласно методике, описанной в работе [19]. Навеску образца массой 500 мг помещали во фторопластовые стаканы, добавляли 2 мл $\mathrm{HNO}_{3}$ (ос.ч.) и нагревали до $90{ }^{\circ} \mathrm{C}$ в течение 20 мин. под крышками, затем нагревание прекращали, добавляли 10 мл НF (ос.ч.) и оставляли на ночь. На следующий день стаканы нагревали под крышками в течение 1 ч, затем крышки снимали и растворы упаривали до влажных солей. Туда же добавляли 2 мл $\mathrm{HNO}_{3}$ и 2 мл $\mathrm{HClO}_{4}$ и вновь упаривали до влажных солей. Затем осадок обрабатывали сначала 5 мл конц. $\mathrm{HCl}$ (ос.ч.), затем 5 мл $6 \mathrm{M} \mathrm{HCl}$, упаривая каждый раз до влажных солей. Полученный осадок растворяли в $1 \mathrm{M} \mathrm{HCl}$. Раствор количественно переводили на объем 25 мл $1 \mathrm{M}$ раствором $\mathrm{HCl}$. Разложенные образцы анализировали методом ИСП-МС по методике [18].

\section{Определение РЗЭ и ВЗЭ методом РФА-СИ}

без химической пробоподготовки

Содержания РЗЭ и ВЗЭ в образцах определяли методом РФА-СИ, который реализован на станции элементного анализа ВЭПП-3 (режим ускорителя 2 ГэВ, ток ускоренных электронов 100 мА) в Сибирском центре синхротронного излучения ИЯФ СО РАН (аналитик Ю.П. Колмогоров). Была применена энергодисперсионная рентгенооптическая схема РФА-СИ в двух режимах первичного монохроматического излучения 33 кэВ [20]. Методика проведения анализа описана в работах [21-23]. Расчет содержаний и контроль точности выполняется методом внешнего стандарта. В качестве стандарта для руд использовали стандартные образцы 
ОСО 250-91 (НФС-23, руда редкоземельная, ВИМС, Россия), для пород - ГСО 521-84П (СГД-1А, габбро-эссекситовое, ИГХ СО РАН, Россия) и ГСО 8670-2005 (СГД-2А, габбро-эссекситовое, ИГХ СО РАН, Россия).

Образец ТР-48 с рудными содержаниями РЗЭ не анализировали методом ИСП-МС после сплавления с $\mathrm{Na}_{2} \mathrm{O}_{2}$, чтобы избежать загрязнения прибора. Содержания $\mathrm{Sc}, \mathrm{Hf}$, Та методом РФА-СИ не определяли из-за инструментальных ограничений, а в образцах TP-37 и TP-215 La$\mathrm{Lu}$ не были определены из-за низких содержаний и отсутствия подходящего стандарта.

Минеральный состав образцов устанавливали рентгенофазовым анализом с использованием порошкового рентгеновского дифрактометра ARL X'TRA (ThermoFisher Scientific, Швейцария). Анализ выполняли в ИГМ СО РАН, аналитик Л.В. Мирошниченко. Состав и микроморфологию минеральных зерен исследовали в аналогичных породах на сканирующем электронном микроскопе MIRA 3 LMU (Tescan Orsay Holding) с системами микроанализа Aztec Energy/INCA Energy 450+ ХMax 80 и INCA Wave 500 (Oxford Instruments Nanoanalysis $\mathrm{Ltd})$, позволяющими изучать наноразмерные частицы (Аналитический центр ИГМ СО РАН). Условия проведения исследований: ускоряющее напряжение - 20 кВ, ток зонда - 1.5 нА. При данных режимах измерения разрешение рентгеновского спектрометра составляет 126-127 эВ на линии $\mathrm{MnKa}$, а размер зонда - 12 нм. Локальность анализа определяется размером области генерации рентгеновского излучения, которая достигает величины 3-5 мкм, в зависимости от среднего атомного номера образца и длины волны характеристического рентгеновского излучения. Время набора спектра на кобальте при количественной оптимизации и при определении состава минералов составляло $60 \mathrm{c}$.

\section{Результаты и их обсуждение}

Выбранные для экспериментов образцы отличаются содержанием исследуемых элементов и минеральным составом.

Образец ТР-37 (скважина 6151, глубина 62.6-64.1 м) представляет собой пермские континентальные угленосные отложения, перекрывающие богатые руды массива Томтор. Основу пород составляют минералы группы каолинита с небольшой примесью гидрослюд. Присутствуют калиевый полевой шпат, гетит. Содержание оксидов титана в образцах столь высоко, что надежно диагностируется рентгенофазовым анализом как анатаз и рутил. Рутил содержит примесь $\mathrm{Nb}$, на краях зерен содержание элемента может достигать 8-10 масс. \%. Значительную долю составляют минералы группы крандаллита как в виде крупных обособлений или обломков, так и в виде основной массы. Состав минералов группы крандаллита неоднороден. Может преобладать горсейкситовый (Ba) минал, но встречается и преобладание крандаллитового (Са) минала. Наблюдается значительное количество цирконов метамиктного облика. Редко можно видеть обломки хромшпинелидов, пирохлора и трубчатые галлуазит-монацитовые агрегаты, характерные для богатых REE-Nb руд [15]. Присутствуют сульфиды. Основные породообразующие оксиды - $\mathrm{SiO}_{2}$ и $\mathrm{Al}_{2} \mathrm{O}_{3}$ (табл. 1). Содержание $\mathrm{TiO}_{2}$ составляет 4 \%.

Образец ТР-48 (скважина 6151, глубина 77.3-77.8 м) представляет собой богатые ниобийредкоземельные руды. Минеральный состав руд включает более 80 минералов: оксиды (пирохлор, гетит, гематит, рутил, ильменорутил), фосфаты (монацит, минералы группы крандаллита, фторапатит, ксенотим), карбонаты (сидерит), сульфиды (пирит, галенит, сфалерит, халькопи-

$$
-597-
$$


Таблица 1. Химический состав (полный силикатный анализ) исследуемых образцов по данным РФА полного силикатного анализа, масс. \%

Table 1. Chemical composition (whole-rock silicate analysis) of the tested samples according to XRF, wt. \%

\begin{tabular}{|c|c|c|c|c|c|c|c|}
\hline Компонент & ТР-37 & ТР-48 & ТР-215 & Компонент & ТР-37 & ТР-48 & ТР-215 \\
\hline $\mathrm{SiO}_{2}$ & 44.68 & 8.64 & 2.29 & $\mathrm{~V}_{2} \mathrm{O}_{5}$ & 0.06 & 0.81 & 0.07 \\
\hline $\mathrm{Al}_{2} \mathrm{O}_{3}$ & 32.37 & 18.18 & 0.09 & $\mathrm{BaO}$ & 0.57 & 1.86 & 0.12 \\
\hline $\mathrm{K}_{2} \mathrm{O}$ & 4.06 & 0.34 & 0.06 & $\mathrm{SrO}$ & 0.09 & 2.43 & 0.37 \\
\hline $\mathrm{Na}_{2} \mathrm{O}$ & 0.05 & $<0.04$ & $<0.04$ & $\mathrm{P}_{2} \mathrm{O}_{5}$ & 0.80 & 12.04 & 2.86 \\
\hline $\mathrm{Fe}_{2} \mathrm{O}_{3}$ & 1.55 & 21.07 & 7.23 & $\mathrm{ZnO}$ & 0.03 & 0.10 & 0.30 \\
\hline $\mathrm{MgO}$ & 0.07 & 0.16 & 1.26 & $\mathrm{NiO}$ & 0.02 & 0.11 & 0.02 \\
\hline $\mathrm{CaO}$ & 0.32 & 1.79 & 47.67 & $\mathrm{Y}_{2} \mathrm{O}_{3}$ & 0.005 & 0.395 & 0.027 \\
\hline $\mathrm{MnO}$ & 0.04 & 0.13 & 1.07 & $\mathrm{REE}_{2} \mathrm{O}_{3}$ & 0.06 & 10.81 & 0.57 \\
\hline $\mathrm{TiO}_{2}$ & 4.07 & 2.01 & 0.04 & LOI & 10.66 & 12.59 & 35.32 \\
\hline $\mathrm{Nb}_{2} \mathrm{O}_{5}$ & 0.05 & 5.76 & 0.23 & Сумма & 99.62 & 99.51 & 99.59 \\
\hline
\end{tabular}

рит), силикаты (каолинит, гидрослюды) $[16,17]$. Но основу руд составляют гетит, монацит и минералы группы крандаллита, пирохлор, оксиды Ті. Руды тонкослоистые и криптозернистые, более $70 \%$ зерен имеют размер $<1 \mu \mathrm{m}$ [15]. Основные породообразующие оксиды $-\mathrm{Fe}_{2} \mathrm{O}_{3}$ и $\mathrm{Al}_{2} \mathrm{O}_{3}$ (табл. 1). Содержания $\mathrm{REE}_{2} \mathrm{O}_{3}$ составляют $10 \%, \mathrm{P}_{2} \mathrm{O}_{5}-12 \%, \mathrm{Nb}_{2} \mathrm{O}_{5}-5.8 \%, \mathrm{TiO}_{2}-2 \%$.

Образец ТР-215 (скважина 6151, глубина 491-505 м) представлен карбонатитами. Рентгенофазовый анализ показывает резкое преобладание в породе кальцита с небольшой примесью других карбонатов (анкерита, родохрозита и доломита). Присутствуют апатит, пирохлор, гетит, кварц, флюорит. Самыми распространенными акцессорными минералами являются карбонаты редкоземельных элементов (бастнезит, паризит), оксиды Ті (рутил, как правило $\mathrm{Nb}$ содержащий). Повсеместно встречается пирит, иногда сфалерит. Кварц, флюорит и сульфиды развиваются по трещинам в породе. Содержание $\mathrm{CaO}$ равно $47.7 \%, \mathrm{Fe}_{2} \mathrm{O}_{3}-7.2 \%, \mathrm{P}_{2} \mathrm{O}_{5}-2.9 \%$, $\mathrm{SiO}_{2}$ от $2.3 \%$ (табл. 1).

В первую очередь были проанализированы стандартные образцы редкоземельных руд методом ИСП-АЭС после сплавления с $\mathrm{Na}_{2} \mathrm{O}_{2}$. Достоверные данные, удовлетворяющие показателям точности, предъявляемым к методикам согласно ОСТ 41-08-212-12 (табл. 2), были получены для всех элементов с аттестованными содержаниями, кроме Tb, Er, Tm, Sc. Чувствительность метода ИСП-АЭС не позволяет определять низкие содержания $\mathrm{Lu}$ (на уровне $\mathrm{n} \cdot 10^{-4}$ масс. \%), а в случае $\mathrm{Sm}, \mathrm{Gd}, \mathrm{Ho}, \operatorname{Pr}$ при их достаточно высоких содержаниях, достигающих порядка $n \cdot 10^{-3}-n \cdot 10^{-2}$ масс. \%, чувствительность метода, по-видимому, значительно падает из-за межэлементных и матричных влияний [24]. Известно, что межэлементные и матричные влияния являются одним из основных недостатков методов ИСП-АЭС, изучению которых посвящено большое количество работ [25]. Кроме того, применение в качестве химической пробоподготовки сплавления с $\mathrm{Na}_{2} \mathrm{O}_{2}$ приводит к еще большему ухудшению чувствительности метода ИСП-АЭС. Это вызвано тем, что в растворах с высоким содержанием легкоионизируемых в плазме элементов (например, при превышении концентрации Na в растворе 500 мг/л) возникают матричные влияния, мешающие определению микроколичеств других элементов [25]. 
Таблица 2. Измеренные методом ИСП-АЭС после сплавления с $\mathrm{Na}_{2} \mathrm{O}_{2}$ и аттестованные содержания Р3Э (масс. \%) в стандартных образцах $(\mathrm{P}=0.95, \mathrm{n}=3)$

Table 2. Contents of REE (wt. \%) determined by the ICP-AES after fusion with $\mathrm{Na}_{2} \mathrm{O}_{2}$ and reference in certified reference samples $(\mathrm{P}=0.95, \mathrm{n}=3)$

\begin{tabular}{|c|c|c|c|c|c|c|}
\hline \multirow{2}{*}{ Элемент } & \multicolumn{2}{|c|}{ ОСО $250-91$} & \multicolumn{2}{c|}{ OCO 755-16 } & \multicolumn{2}{c|}{ OCO 758-16 } \\
\cline { 2 - 7 } & $\mathrm{C}_{\text {аттест. }}$ & $\mathrm{C}_{\text {измер. }}$ & $\mathrm{C}_{\text {аттест. }}$ & $\mathrm{C}_{\text {измер. }}$ & $\mathrm{C}_{\text {аттест. }}$ & $\mathrm{C}_{\text {измер. }}$ \\
\hline $\mathrm{Sc}$ & 0.064 & $\mathrm{nd}$ & 0.0063 & $\mathrm{nd}$ & 0.0027 & $\mathrm{nd}$ \\
\hline $\mathrm{Y}$ & 0.75 & 0.77 & 0.095 & 0.093 & 0.15 & 0.15 \\
\hline $\mathrm{Zr}$ & 0.16 & 0.20 & 0.038 & 0.047 & 0.043 & 0.046 \\
\hline $\mathrm{Nb}$ & 4.7 & 3.7 & 0.50 & 0.40 & 0.26 & 0.20 \\
\hline $\mathrm{La}$ & 5.47 & 5.39 & 0.75 & 0.74 & 2.02 & 2.05 \\
\hline $\mathrm{Ce}$ & 10.81 & 10.3 & 1.31 & 1.22 & 2.66 & 2.55 \\
\hline $\mathrm{Pr}$ & 1.15 & 1.07 & 0.133 & 0.099 & 0.22 & 0.19 \\
\hline $\mathrm{Nd}$ & 3.67 & 4.44 & 0.45 & 0.51 & 0.65 & 0.71 \\
\hline $\mathrm{Sm}$ & 0.44 & $\mathrm{nd}$ & 0.059 & 0.072 & 0.075 & $\mathrm{nd}$ \\
\hline $\mathrm{Eu}$ & 0.123 & 0.12 & 0.016 & 0.015 & 0.018 & 0.019 \\
\hline $\mathrm{Gd}$ & 0.26 & 0.29 & 0.040 & 0.026 & 0.048 & 0.033 \\
\hline $\mathrm{Tb}$ & 0.039 & $\mathrm{nd}$ & 0.0050 & $\mathrm{nd}$ & 0.0067 & $\mathrm{nd}$ \\
\hline $\mathrm{Dy}$ & 0.17 & 0.18 & 0.023 & 0.026 & 0.0298 & 0.048 \\
\hline $\mathrm{Ho}$ & 0.030 & 0.021 & 0.0038 & $<0.005$ & 0.0054 & $<0.005$ \\
\hline $\mathrm{Er}$ & 0.066 & $\mathrm{nd}$ & 0.0085 & $\mathrm{nd}$ & 0.0134 & $\mathrm{nd}$ \\
\hline $\mathrm{Tm}$ & 0.0077 & $\mathrm{nd}$ & 0.0010 & $\mathrm{nd}$ & 0.0017 & $\mathrm{nd}$ \\
\hline $\mathrm{Yb}$ & 0.045 & 0.057 & 0.0058 & 0.0057 & 0.0096 & 0.012 \\
\hline $\mathrm{Lu}$ & 0.0080 & 0.0081 & 0.00076 & 0.0012 & 0.0013 & 0.0016 \\
\hline
\end{tabular}

Примечание: $\mathrm{nd}$ - элемент не определялся.

Спектральные помехи, вызванные высокими содержаниями одних РЗЭ, мешают определению других РЗЭ с более низкими содержаниями [26]. Содержания Ta, Hf, Th, U не аттестованы в изучаемых стандартных образцах. Невзирая на перечисленные трудности определения, полученные значения указывают на хорошее разложение минералов-носителей РЗЭ примененным методом сплавления с $\mathrm{Na}_{2} \mathrm{O}_{2}$.

При сравнении результатов анализа изучаемых образцов, полученных разными методами, было выявлено несколько закономерностей, несмотря на их разный химический состав (табл. 1). Данные о содержании РЗЭ (табл. 3), полученные методами ИСП-АЭС и ИСП-МС, после различного разложения очень хорошо согласуются между собой, т.е. расхождения между результатами анализа не превышают пределов воспроизводимости, регламентированных по ОСТ 41-08-212-12. Основами минералами - носителями РЗЭ в образцах выступают фосфаты и карбонаты (минералы группы монацита и бастнезита), которые хорошо разлагаются в кислотах. Небольшие расхождения установлены для $\mathrm{Nd}, \mathrm{Sm}$ и $\mathrm{Eu}$, выявить причины этого еще предстоит, но различия не меняют общих геохимических закономерностей распределения.

Существенно расходящиеся результаты были получены для ВЗЭ при использовании различных методов разложения (табл. 4). Содержание Zr в образце ТР-37 (континентальные от- 
Таблица 3. Содержания (г/т) редкоземельных элементов в исследуемых образцах $(\mathrm{P}=0.95, \mathrm{n}=2$ по каждому методу)

Table 3. Rare earth elements contents $(\mathrm{g} / \mathrm{t})$ in the tested samples $(\mathrm{P}=0.95, \mathrm{n}=2$ for each method)

\begin{tabular}{|c|c|c|c|c|c|c|c|c|}
\hline \multirow{3}{*}{$\begin{array}{c}\text { Образец } \\
\text { Метод } \\
\text { разложения } \\
\text { Метод } \\
\text { анализа }\end{array}$} & \multicolumn{3}{|c|}{ TP-37 } & \multicolumn{3}{|c|}{ TP-215 } & \multicolumn{2}{|c|}{ TP-48 } \\
\hline & \multirow{2}{*}{$\begin{array}{c}\begin{array}{c}\text { Кислотное } \\
\text { разложение }\end{array} \\
\text { ИСП-МС }\end{array}$} & \multicolumn{2}{|c|}{$\begin{array}{c}\text { Сплавление } \\
\text { с } \mathrm{Na}_{2} \mathrm{O}_{2}\end{array}$} & \multirow{2}{*}{$\begin{array}{c}\begin{array}{c}\text { Кислотное } \\
\text { разложение }\end{array} \\
\text { ИСП-МС }\end{array}$} & \multicolumn{2}{|c|}{$\begin{array}{c}\text { Сплавление } \\
\text { с Na}{ }_{2} \mathrm{O}_{2}\end{array}$} & \multirow{2}{*}{$\begin{array}{c}\begin{array}{c}\text { Кислотное } \\
\text { разложение }\end{array} \\
\text { ИСП-МС }\end{array}$} & \multirow{2}{*}{$\begin{array}{c}\begin{array}{c}\text { Сплавление } \\
\text { с } \mathrm{Na}_{2} \mathrm{O}_{2}\end{array} \\
\text { ИСП-АЭС }\end{array}$} \\
\hline & & $\begin{array}{l}\text { ИСП- } \\
\text { АЭС }\end{array}$ & $\begin{array}{c}\text { ИСП- } \\
\text { МС }\end{array}$ & & $\begin{array}{c}\text { ИСП- } \\
\text { АЭС }\end{array}$ & $\begin{array}{c}\text { ИСП- } \\
\text { МС }\end{array}$ & & \\
\hline $\mathrm{La}$ & 480 & 460 & 480 & 1400 & 1400 & 1600 & 25500 & 26000 \\
\hline $\mathrm{Ce}$ & 790 & 770 & 770 & 2700 & 2800 & 2500 & 48000 & 51000 \\
\hline $\mathrm{Pr}$ & 80 & bdl & 77 & 330 & bdl & 260 & 5900 & 5100 \\
\hline $\mathrm{Nd}$ & 260 & bdl & 300 & 1000 & 990 & 1100 & 18000 & 20000 \\
\hline $\mathrm{Sm}$ & 40 & bdl & 50 & 100 & bdl & 160 & 2000 & 2300 \\
\hline $\mathrm{Eu}$ & 13.0 & 10 & 15 & 29 & 20 & 33 & 480 & 590 \\
\hline $\mathrm{Gd}$ & 41.0 & bdl & 42 & 87 & bdl & 84 & 1500 & 1600 \\
\hline $\mathrm{Tb}$ & 5.7 & nd & 5.4 & 10 & nd & 10 & 170 & nd \\
\hline Dy & 26.0 & 20 & 26 & 48 & 60 & 46 & 740 & 760 \\
\hline Ho & 4.3 & bdl & 4.6 & 10 & bdl & 8.4 & 125 & 88 \\
\hline $\mathrm{Er}$ & 10 & nd & 10 & 20 & nd & 22 & 320 & nd \\
\hline $\mathrm{Tm}$ & 1.4 & nd & 1.2 & 2.7 & nd & 2.7 & 42 & nd \\
\hline $\mathrm{Yb}$ & 7.6 & 10 & 7.8 & 15 & 15 & 16 & 220 & 250 \\
\hline $\mathrm{Lu}$ & 1.0 & bdl & 1.0 & 1.9 & bdl & 1.7 & 27 & 35 \\
\hline
\end{tabular}

Примечание: nd - элемент не определялся, bdl - ниже предела обнаружения.

ложения пермского возраста), определенное методом ИСП-МС после кислотного разложения, составило 460 г/т, что существенно меньше, чем содержания, полученные методом РФА-СИ (1100 г/т) и методами ИСП-АЭС и ИСП-МС после сплавления с $\mathrm{Na}_{2} \mathrm{O}_{2}$ (1200 и 1350 г/т соответственно). В образце ТР-215 (кальцитовые карбонатиты) после кислотного разложения содержание $\mathrm{Zr}$ составило 31 г/т, в то время как содержания, полученные методами РФА-СИ и ИСП-АЭС, ИСП-МС после сплавления с $\mathrm{Na}_{2} \mathrm{O}_{2}$, значительно выше и сопоставимы между собой $(150,130$ и 155 г/т соответственно, табл. 4). Самые существенные различия в содержании $\mathrm{Zr}$ были установлены для образца ТР-48 (богатые монацит-крандаллит-пирохлоровые руды). Содержание, полученное методом ИСП-МС после кислотного вскрытия, составило только 6 г/Т, в то время как содержания, полученные методами РФА-СИ и ИСП-АЭС, выше более чем на два порядка и равняются 1000 и 14000 г/т.

Наблюдаются очевидные различия между разными образцами. Если в образцах ТР-215 и ТР-48 полученные после кислотного вскрытия содержания Zr сопоставимы и составляют 31 и 6 г/т, невзирая на истинное содержание элемента в пробе, то в образце ТР-37 содержание циркония было равным 460 г/т. Минералогическими исследованиями было выявлено, что в образцах карбонатитов и богатых руд (ТР-215 и ТР-48) содержится свежий магматический циркон, а в пермских отложениях - минерал пористый и метамиктный. Возможно, последний лучше поддается кислотному разложению. Однако данные о содержании $\mathrm{Hf}$, примесного в цирконе элемента, полученные после кислотного разложения и сплавления с $\mathrm{Na}_{2} \mathrm{O}_{2}$, 
Таблица 4. Содержания (г/т) Y, Sc и высокозарядных элементов в исследуемых образцах (P=0.95, n=2 по каждому методу)

Table 4. Content of $\mathrm{Y}, \mathrm{Sc}$, and high field strength elements $(\mathrm{g} / \mathrm{t})$ in the tested samples $(\mathrm{P}=0.95, \mathrm{n}=2$ for each method)

\begin{tabular}{|c|c|c|c|c|c|c|c|c|c|c|c|}
\hline Образец & \multicolumn{4}{|c|}{ TP-37 } & \multicolumn{4}{|c|}{ TP-215 } & \multicolumn{3}{|c|}{ TP-48 } \\
\hline $\begin{array}{l}\text { Метод } \\
\text { разло- }\end{array}$ & \multirow{2}{*}{$\begin{array}{l}\text { РФА- } \\
\text { СИ }\end{array}$} & \multirow{2}{*}{$\begin{array}{c}\text { Кислотное } \\
\text { разложение }\end{array}$} & \multicolumn{2}{|c|}{$\begin{array}{c}\text { Сплавление } \\
\text { с Na } \mathrm{O}_{2}\end{array}$} & \multirow{2}{*}{$\begin{array}{c}\text { РФА- } \\
\text { СИ }\end{array}$} & \multirow{2}{*}{$\begin{array}{c}\text { Кислотное } \\
\text { разложение }\end{array}$} & \multicolumn{2}{|c|}{$\begin{array}{c}\text { Сплавление } \\
\text { с } \mathrm{Na}_{2} \mathrm{O}_{2}\end{array}$} & \multirow{2}{*}{$\begin{array}{l}\text { РФА- } \\
\text { СИ }\end{array}$} & \multirow{2}{*}{$\begin{array}{c}\text { Кислотное } \\
\text { разложение }\end{array}$} & \multirow{2}{*}{$\begin{array}{c}\text { Сплавление } \\
\text { с } \mathrm{Na}_{2} \mathrm{O}_{2}\end{array}$} \\
\hline $\begin{array}{c}\text { Метод } \\
\text { анализа }\end{array}$ & & & $\begin{array}{l}\text { ИСП- } \\
\text { АЭС }\end{array}$ & $\begin{array}{l}\text { ИСП- } \\
\text { МС }\end{array}$ & & & $\begin{array}{l}\text { ИСП- } \\
\text { АЭС }\end{array}$ & $\begin{array}{c}\text { ИСП- } \\
\text { МС }\end{array}$ & & & \\
\hline $\mathrm{Sc}$ & nd & 30 & nd & 29 & nd & 17.5 & nd & 18 & nd & 200 & nd \\
\hline Y & 120 & 110 & 91 & 160 & 140 & 225 & 200 & 280 & 3200 & 3300 & 3500 \\
\hline $\mathrm{Zr}$ & 1100 & 460 & 1200 & 1350 & 150 & 31 & 130 & 155 & 1000 & 6 & 1400 \\
\hline $\mathrm{Nb}$ & 780 & 580 & 890 & 1100 & 1600 & 45 & 1450 & 1600 & 43000 & 59 & 45000 \\
\hline $\mathrm{Hf}$ & nd & 11 & nd & 16 & nd & 2.2 & nd & 2.5 & nd & 3.2 & nd \\
\hline $\mathrm{Ta}$ & nd & 7.6 & nd & 13 & nd & 0.20 & nd & 1.2 & nd & 0.4 & nd \\
\hline Th & 75 & 55 & nd & 67 & 120 & 93 & nd & 176 & 370 & 150 & nd \\
\hline $\mathrm{U}$ & 2.6 & 2.6 & nd & 9.6 & bdl & 3.4 & nd & 3.2 & 130 & 9 & nd \\
\hline
\end{tabular}

Примечание: nd - элемент не определялся, bdl - ниже предела обнаружения.

более сопоставимы между собой, значения после сплавления выше, но разница не составляет порядки (табл. 4). Таким образом, можно предположить или различия стабильности $\mathrm{Zr}$ в растворе после разложения в зависимости от состава образца, или неустойчивость в обоих растворах Hf.

Максимальная разница в данных о содержании в зависимости от метода вскрытия была установлена для Nb. Причем данные о содержании элемента в образце ТР-37 после кислотного разложения, как и в случае с Zr, оказались ближе, чем в образцах ТР-215 и ТР-48. После кислотного вскрытия в образце ТР-37 выявлены данные о содержании Nb 580 г/т, при этом результаты РФА-СИ и ИСП-АЭС, ИСП-МС после сплавления с $\mathrm{Na}_{2} \mathrm{O}_{2}$ варьируют достаточно - 780, 890 и 1120 г/т, но все выше. Очень существенные различия наблюдаются в данных о содержании Nb в образце ТР-215, определенных разными методами и при различном вскрытии. После кислотного вскрытия метод ИСП-МС показал значение содержания 45 г/т, РФА-СИ - 1600 г/т, ИСП-АЭС, ИСП-МС после сплавления с $\mathrm{Na}_{2} \mathrm{O}_{2}-1450$ и 1590 г/т. И самые большие различия, достигающие трех порядков, наблюдаются в данных для образца богатых руд ТР-48: ИСП-МС после кислотного вскрытия - 59 г/т, РФА-СИ - 43000 г/т, ИСП-АЭС после сплавления с $\mathrm{Na}_{2} \mathrm{O}_{2}-45000$ г/т. В первую очередь следует отметить, что в изучаемых образцах различаются минералы-носители $\mathrm{Nb}$. Если в образце TP-37 Nb в основном содержится в виде примеси в рутиле, то в образце TP-215 присутствуют как Nb-содержащий рутил, так и пирохлор, а в образце ТP-48 пирохлор резко преобладает.

Данные о содержании Та намного ближе между собой, чем содержания Nb. Та содержится в образцах в виде небольшой примеси в пирохлоре. При кислотном вскрытии в образцах установлены содержания ниже, чем при сплавлении. В образце ТР-37, который состоит преимущественно из каолинита, содержания ниже. Аналогичные закономерности выявляются 
для содержаний Th и U. Элементы содержатся в основном в минералах группы монацита, которые хорошо разлагаются и кислотным вскрытием, и сплавлением с $\mathrm{Na}_{2} \mathrm{O}_{2}$. Но при кислотном вскрытии содержания Тh существенно ниже, чем определенные другими методами или после сплавления с $\mathrm{Na}_{2} \mathrm{O}_{2}$, следовательно, потери Тh происходят уже после разложения пробы и их следует объяснять нестабильностью элемента в растворе.

Таким образом, наблюдается занижение содержаний В3Э после кислотного разложения. Согласно литературным данным, систематическое занижение результатов анализа В3Э, полученных методом ИСП-МС после кислотного разложения, может быть вызвано, во-первых, наличием в составе образцов «упорных» минералов, требующих более жестких условий химической пробоподготовки $[13,14]$. Известно, что полное вскрытие «упорных» минералов достигается при применении методик со сплавлением [11].

Второй важной причиной занижения результатов является то, что в ходе разложения смесью минеральных кислот возможно образование нерастворимых фторидов $\mathrm{Ca}, \mathrm{Al}, \mathrm{Mg}, \mathrm{Fe}$. Экспериментально установлено, что осаждение фторидов в ходе кислотного разложения сопровождается также осаждением фторидов РЗЭ и В3Э [27]. Поэтому в процессе кислотного разложения следует добавлять рассчитанное количество фтороводородной кислоты для растворения силикатов [19], а для стабилизации в растворе ВЗЭ после сплавления добавляют следовые количества HF [18]. Проведенные эксперименты показали, что после стандартной методики кислотного разложения ИСП-МС демонстрирует занижение содержаний ВЗЭ в образце с высоким содержанием $\mathrm{Al}$ и $\mathrm{Si}$, но результаты оказываются заниженными не более чем в 2 раза. В случае низких содержаний $\mathrm{Al}$ в образце а главное $\mathrm{Si}$, занижение по некоторым элементам составляет порядки. Очевидно, что HF, которая должна была расходоваться на удаление кремния, частично остается, что приводит к формированию фторидов В3Э.

Таким образом, определение высоких содержаний РЗЭ и ВЗЭ методами ИСП-АЭС и ИСПМС остается сложной задачей и требует дальнейших исследований в этом направлении. При выборе метода химической пробоподготовки предпочтение исследователей до сих пор отдается сплавлению, несмотря на энерго- и трудозатратность метода, высокую минерализацию конечных разложенных растворов, высокий уровень контрольного опыта [11], при выборе метода анализа - ИСП-МС - благодаря высокой чувствительности метода [1].

При определении рудных содержаний РЗЭ и ВЗЭ предпочтительным является использование метода ИСП-АЭС. Однако для получения достоверных результатов необходимо модифицировать применяемые методы химической пробоподготовки: отделять элементы от матрицы после сплавления [11] либо интенсифицировать кислотное разложение применением микроволновой техники или более высококипящих реагентов [28, 29].

В результате проведенных исследований с образцами Nb-REE-руд Томторского месторождения нами предложена методика сплавления с $\mathrm{Na}_{2} \mathrm{O}_{2}$ геологических образцов с высоким содержанием «упорных» минералов, при котором достигается полное вскрытие пробы. В отличие от сплавления с $\mathrm{LiBO}_{2}$ в платиновых тиглях, реализованном в работе [18], методика, где используются корундовые стаканчики, позволяет анализировать образцы, содержащие сульфиды. Однако неизбежное разрушение корундовых стаканчиков в процессе сплавления приводит к загрязнению проб, таким образом, сохраняется необходимость использования комплекса методов для получения достоверных результатов. 


\section{Благодарности / Acknowledgements}

Работа выполнена в рамках проекта РНФ № 18-17-00120. Работа выполнена в «ЦКП Многоэлементных и изотопных исследований ИГМ СО РАН».

The study was supported by grant 18-77-10056 from the Russian Science Foundation. The analyses were performed at the Analytical Center for multi-elemental and isotope research SB RAS (Novosibirsk, Russia).

\section{Список литературы / References}

1. Balaram V. Rare earth elements: A review of applications, occurrence, exploration, analysis, recycling, and environmental impact. Geoscience Frontiers 2019. Vol. 10(4), P. 1285-1303.

2. Zawisza B., Pytlakowska K., Feist B., Polowniak M., Kita A., Sitko R. Determination of rare earth elements by spectroscopic techniques: a review. Journal of Analytical Atomic Spectrometry 2011. Vol. 26(12), P. 2373-2390.

3. Fisher A., Kara D. Determination of rare earth elements in natural water samples - A review of sample separation, preconcentration and direct methodologies. Analytica chimica acta 2016. Vol. 935, P. 1-29.

4. Толстов А.В., Коноплев А.Д., Кузьмин В.И. Особенности формирования уникального редкометального месторождения «Томтор» и оценка перспектив его освоения. Разведка и охрана недр 2011. №. 6, C. 20-26. [Tolstov A.V., Konoplev A.D., Kuzmin V.I. The peculiarities of forming the unique rare metal deposit Tomtor and estimation of perspectives of its industrial. Prospect and protection of mineral resources 2011. № 6, P. 20-26. (In Russ.)]

5. Похиленко Н.П., Крюков В.А., Толстов А.В., Самсонов, Н.Ю. Томтор как приоритетный инвестиционный проект обеспечения России собственным источником редкоземельных элементов. Всероссийский экономический журнал ЭКО 2014. T. 44(2), С. 22-35. [Pokhilenko N.P., Kryukov V.A., Tolstov A.V., Samsonov N.Yu. Tomtor as priority investment project to provide Russia with its own source of rare earth elements. ECO 2014. Vol. 44(2), P. 22-35. (In Russ.)]

6. Podkopaev O.I., Balakchina E.S., Losev V.N., Kopytkova S.A., Kulagin V.A., Shimanskii A.F. Rare Earth Elements in the Lignite Ash Determination Method Development. Journal of Siberian Federal University. Engineering \& Technologies 2016. Vol. 9(8), P. 1238-1246.

7. Pagano G., Guida M., Tommasi F., Oral R. Health effects and toxicity mechanisms of rare earth elements-Knowledge gaps and research prospects. Ecotoxicology and environmental safety 2015. Vol. 115, P. 40-48.

8. Rim K.T. Effects of rare earth elements on the environment and human health: a literature review. Toxicology and Environmental Health Sciences 2016. Vol. 8(3), P. 189-200.

9. Weyer S., Münker C., Rehkämper M., Mezger K. Determination of ultra-low Nb, Ta, Zr and $\mathrm{Hf}$ concentrations and the chondritic $\mathrm{Zr} / \mathrm{Hf}$ and $\mathrm{Nb} / \mathrm{Ta}$ ratios by isotope dilution analyses with multiple collector ICP-MS. Chemical Geology 2002. Vol. 187(3-4), P. 295-313.

10. Iwasaki K., Fuwa K., Haraguchi H. Simultaneous determination of 14 lanthanides and yttrium in rare earth ores by inductively-coupled plasma atomic emission spectrometry. Analytica chimica acta 1986. Vol. 183, P. 239-249.

11. Pinto F.G., Junior R.E., Saint'Pierre T.D. Sample preparation for determination of rare earth elements in geological samples by ICP-MS: a critical review. Analytical letters 2012. Vol. 45(12), P. 1537-1556.

$$
-603-
$$


12. Seregina I.F., Volkov A.I., Ossipov K., Bolshov M.A. Characterization of REE-Nb ores by a combination of spectrochemical techniques. Spectrochimica Acta Part B: Atomic Spectroscopy 2018. Vol. 148, P. 172-182.

13. Helmeczi E., Wang Y., Brindle I.D. A novel methodology for rapid digestion of rare earth element ores and determination by microwave plasma-atomic emission spectrometry and dynamic reaction cell-inductively coupled plasma-mass spectrometry. Talanta 2016. Vol. 160, P. 521-527.

14. Bezerra de Oliveira A.L., Afonso J.C., da Silva L., Alcover Neto A., Castro Carneiro M., Dias da Silva L.I., Couto Monteiro M.I. Hydrofluoric Acid-Free Digestion of Geological Samples for the Quantification of Rare Earth Elements by Inductively Coupled Plasma-Optical Emission Spectrometry. Geostandards and Geoanalytical Research 2019. Vol. 43(4), P. 689-699.

15. Lazareva E.V., Zhmodik S.M., Dobretsov N.L., Tolstov A.V., Shcherbov B.L., Karmanov N.S., Gerasimov E.Yu., Bryanskaya A.V. Main minerals of abnormally high-grade ores of the Tomtor deposit (Arctic Siberia). Russian Geology and Geophysics 2015. Vol. 56(6), P. 844-873.

16. Коноплев А.Д., Толстов А.В., Васильев А.Т., Нечелюстов Г.Н., Кузьмин В.И., Скляднева В.М., Дубинчук В.Т., Коноплева Е.В., Сидоренко Г.А. Особенности локализации редкометального оруденения на месторождении «Томтор». Редкометально-урановое рудообразование в осадочных породах. М.: Наука, 1995, С. 223-241. [Konoplev A.D., Tolstov A.V., Vasil'ev A.T., Nechelyustov G.N., Kuz'min V.I., Sklyadneva V.M., Dubinchuk V.T., Konopleva E.V., Sidorenko G.A. Peculiarities of localization of rare-metal mineralization at the Tomtor deposit. Rare-metal-uranium ore formation in sedimentary rocks. M., Nauka, 1995, P. 223-241. (In Russ.)]

17. Минерагения кор выветривания карбонатитов. Методическое руководство. Под ред. Н.В. Межеловского. М.: ГЕОКАРТ, ГЕОС, 2011. 308 с. [Minerageny of carbonatite weathering crust. Methodical guide. Under Ed. N.V. Mezhelovsky. Moscow: GEOKART, GEOS, 2011. 308 p. (In Russ.)]

18. Nikolaeva I.V., Palesskii S.V., Koz'menko O.A., Anoshin G.N. Analysis of geologic reference materials for REE and HFSE by inductively coupled plasma-mass spectrometry (ICP-MS). Geochemistry International 2008. Vol. 46(10), P. 1016-1022.

19. Liberatore P.A. Determination of trace elements in geological samples by ICP-AES. Varian ICP-AES Instruments at Work 1994, P. 1-9.

20. Baryshev V.B., Gavrilov N.G., Daryin A.V., Zolotarev K.V., Kulipanov G.N., Mezentsev N.A., Terekhov Y.V. Status of X-ray fluorescence elemental analysis at VEPP-3. Nuclear Instruments and Methods in Physics Research Section A: Accelerators, Spectrometers, Detectors and Associated Equipment 1989. Vol. 282(2-3), P. 570-575.

21. Phedorin M.A., Bobrov V.A., Zolotarev K.V. Synchrotron radiation X-ray fluorescence analysis of VEPP-3 of the bottom sediments of Lake Baikal to perform a paleoclimatic reconstruction. Nuclear instruments and methods in physics research section A: Accelerators, Spectrometers, Detectors and Associated Equipment 1998. Vol. 405(2-3), P. 560-568.

22. Trounova V.A., Zolotarev K.Z., Baryshev V.B., Phedorin M.A. Analytical possibilities of SRXRF station at VEPP-3 SR source. Nuclear Instruments and Methods in Physics Research Section A: Accelerators, Spectrometers, Detectors and Associated Equipment 1998. Vol. 405(2-3), P. 532-536.

23. Goldberg E.L., Phedorin M.A., Grachev M.A., Bobrov V.A., Dolbnya I.P., Khlystov O.M., Levina O.V., Ziborova G.A. Geochemical signals of orbital forcing in the records of paleoclimates 
found in the sediments of Lake Baikal. Nuclear Instruments and Methods in Physics Research Section A: Accelerators, Spectrometers, Detectors and Associated Equipment 2000. Vol. 448(1-2), P. 384-393.

24. Todolí J.L., Gras L., Hernandis V., Mora J. Elemental matrix effects in ICP-AES. Journal of analytical atomic spectrometry 2002. Vol. 17(2), P. 142-169.

25. Chan G.C.Y., Chan W.T. Plasma-related matrix effects in inductively coupled plasma-atomic emission spectrometry by group I and group II matrix-elements. Spectrochimica Acta Part B: Atomic Spectroscopy 2003. Vol. 58(7), P. 1301-1317.

26. Zuleger E., Erzinger J. Determination of the REE and Y in silicate materials with ICP-AES. Fresenius' Zeitschrift für Analytische Chemie 1988. Vol. 332(2), P. 140-143.

27. Аношкина Ю.В., Асочакова Е.М., Бухарова О.В., Отмахов В.И., Тишин П.А. Оптимизация условий пробоподготовки углеродистых геологических пород для последующего анализа методом масс-спектрометрии с индуктивно-связанной плазмой. Аналитика и контроль 2013. T. 17(1), C. 47-58. [Anoshkina Yu.V., Asochakova E.M., Buharova O.V., Otmahov V.I., Tishin P.A. Optimization of conditions for sample preparation of carbonaceous geological samples for subsequent mass spectrometry with inductively coupled plasma analysis. Analitika \& kontrol' 2013. Vol. 17(1), P. 47-58. (In Russ.)]

28. Корсакова Н.В., Торопченова Е.С., Кригман Л.В., Бударина,Н.В., Кубракова И.В. Анализ силикатных материалов с использованием микроволновой пробоподготовки. Заводская лаборатория. Диагностика материалов 2009. T. 75(4), C. 23-27. [Korsakova N.V., Toropchenova E.S., Krigman L.V., Budarina N.V., Kubrakova I.V. Analysis of silicate materials using microwave sampling. Industrial Laboratory. Diagnostics of Materials 2009. Vol. 75(4), P. 23-27. (In Russ.)]

29. Butler O.T., Cairns W.R.L., Cook J.M., Davidson C.M. 2014 atomic spectrometry update a review of advances in environmental analysis. Journal of Analytical Atomic Spectrometry 2015. Vol. 30(1), P. 21-63. 